\title{
Positive Pelvic Lymph Node
}

National Cancer Institute

\section{Source}

National Cancer Institute. Positive Pelvic Lymph Node. NCI Thesaurus. Code C132079.

A laboratory test result indicating the presence of a pathologic process in a pelvic lymph node. 